\title{
Screening for cognitive impairment in Arabic-speaking Hajj pilgrims
}

\author{
Ahmad S. Alzahrani ${ }^{1,2^{*}}$ (D) Faisal Alhumaidi ${ }^{3}$, Abdulaziz Altowairqi ${ }^{3}$, Waad Al-Malki ${ }^{3}$ and Israa AlFadhli ${ }^{3}$
}

\begin{abstract}
Background: Although cognitive impairment is common in the elderly population, studies investigating its rate in Hajj pilgrims are lacking.

Objectives: To estimate the rate of cognitive impairment among a sample of Arabic-speaking elderly Hajj pilgrims and examine its association with their activities of daily living (ADL).

Methods: A cross-sectional study was conducted during the Hajj season 1438 Hijri Calendar (August 2017). Hajj pilgrims were recruited using a probability sampling method and were interviewed for demographics, the MINI-Cog and the ADL instrument.

Results: Among the 340 recruited pilgrims, 99 (29.2\%) had positive results in the MINI-Cog indicating probable cognitive impairment. In multivariate logistic regression, the educational level (odds ratio (OD) $0.456 ; 95 \% \mathrm{Cl} 0.346$ to 0.598 ) and the need for help during Hajj (OD $0.581 ; 95 \% \mathrm{Cl} 0.342$ to 0.984 ) were found significantly associated with positive MINI-Cog. Although no significant differences in the ADL were found between pilgrims with and without positive MINI-Cog, the scores of the ADL and the MINI-Cog were found to be positively correlated but weak $\left(r_{s}=0.134, P=0.013\right)$ indicating a possible association between better cognitive functions and better ADL performance.

Conclusion: Probable cognitive impairment among Arabic elderly Hajj pilgrims was found to be very common. Further diagnostic studies and studies on the impact of cognitive impairment on the performance of Hajj pilgrims are warranted.
\end{abstract}

Keywords: Cognition, Arab, Hajj, Pilgrim, MINI-Cog, Dementia, Activities of daily living, ADL

\section{Introduction}

Worldwide, cognitive impairment and dementia are common [1]. There are more than 9.9 million new cases of dementia reported each year with an expected doubling each 20 years, reaching 131.5 million in 2050 [2]. Nonetheless, studies investigating the prevalence of cognitive impairment and dementia in the Middle East (ME) countries, where the majority speaks Arabic, are lacking [3]. Ten countries of the ME and North Africa have no data on the rate of dementia [3]. Of the few reported studies, the dementia prevalence rates were 13\% in Saudi Arabia [4], 2 to 5\% in Egypt [5] and 9.8\%

\footnotetext{
*Correspondence: dr_ahmadsz@yahoo.com; ahmad.alzahrani@kfshrc.edu.sa ${ }^{1}$ Mental Health Administration, Neuroscience Center, King Abdullah Medical City, Makkah, Saudi Arabia

${ }^{2}$ Neuroscience Department, King Faisal Specialist Hospital and Research

Center, Jeddah, Saudi Arabia

Full list of author information is available at the end of the article
}

in Arab Israel [6]. Since the majority of patients with dementia are above the age of 65 years, dementia is of a concern in the Arab countries because of the observed rapid ageing in the Arab nations. By 2050, an expected $15 \%$ of the Arab countries' population will constitute of elderly individuals who are 60 years old or older $[7,8]$.

Hajj is a Muslim religious ritual performed by Muslim pilgrims from all over the world at a specific time of the year. Around 2 million Hajj pilgrims gather each year and have to perform sequential steps that require staying at different locations in Makkah city [9]. Those pilgrims have to be in good physical, psychological and cognitive health in order to perform Hajj properly [10-12]. In Hajj, little is known about the prevalence of dementia among pilgrims. In a study which investigated the rate of probable dementia among Malaysian pilgrims in 2006, the estimated rate was found to reach up to $20 \%$ [13]. 
Clinical conditions with cognitive impairment, like dementia, can affect the activities of daily living (ADL), such as dressing, bathing and feeding, hindering not only the abilities to perform simple daily tasks but also more complex duties and activities [14]. In fact, dementia was found to be the most significant contributor to disability in older adults, more than conditions such as stroke, blindness, arthritis and limb impairment [15]. Having a significant cognitive impairment during Hajj may negatively impact the performance and completion of Hajj rituals. Negative consequences associated with dementia that can be of particular importance in Hajj rituals include greater risk of falls, losing track, exhaustion, poor nutrition, dehydration, anxiety, caregiver's burden, morbidity and mortality [16-19].

Although many Hajj pilgrims are elderly, the rate of cognitive impairment and the associated degree of impairment in their ADL have not yet been studied previously. Therefore, the present study aimed to estimate the rate of those pilgrims with probable cognitive impairment and to examine any associations between cognitive impairment and sociodemographic data or difficulties in the ADL. The insight of this study can facilitate better recognition of the problem and promote proactive and strategic actions by the Hajj authorities.

\section{Method}

\section{Design, participants and procedure}

The study was cross-sectional conducted from the 1st of Dhul Hijjah of the year 1438 Hijri Calendar (the 23rd of August 2017) until the 8th of Dhul Hijjah of the year 1438 Hijri Calendar (the 30th of August 2017). Pilgrims who are 60 years old or older, attending Hajj season 1438 Hijri Calendar (August 2017), speak the Arabic language and able to write Arabic numbers were included in the study. Pilgrims were excluded if they did not complete the study questionnaire or refused to participate.

A multi-stage random sampling method was used, stratified by gender. The Hajj organizing "Twafa" establishments of countries where the majority of their pilgrims speak Arabic were approached. These countries were, in alphabetical order, Algeria, Bahrain, Egypt, Eritrea, Iraq, Jordan, Kuwait, Lebanon, Libya, Morocco, Oman, Palestine, Saudi Arabia, Sudan, Syria, Tunisia and Yemen.

A list of offices affiliated with each establishment was sought. Offices were chosen randomly, but in case of difficulties, offices that were ailing to help were approached for convenience. A list of buildings and hotels managed by each office were sought with numbers of registered pilgrims in each. A random sample of buildings was selected, and within each, a pre-specified number of pilgrims were targeted within each building, the pilgrims with even numbers in the pilgrims' list were approached. Those who met the study criteria were included until the prespecified number of pilgrims were completed, satisfying a male to female ratio of 1:1.

\section{Material and instruments}

The study protocol was approved by the Ethics Committee of Security Forces Hospital Program (No. 0124-210817). Before data collection, all participants and their relatives were informed about the study purpose and its procedure. Pilgrims were interviewed for demographics; whether travelling alone or with someone else; whether they think they need help to perform Hajj, by whom, and what the type of help they need; medical history; history of visiting a clinic for memory problem; history of a diagnosis with a disease related to a memory problem; and whether needed medication for memory problems. Then, pilgrims underwent the Mini-Cog [20] and were asked to complete the Arabic version of the ADL instrument either by themselves or by the help of their caregivers/relatives [21].

The Mini-Cog is a 3-min cognitive screening tool that can detect cognitive impairment in older adults. This brief instrument was initially designed for community setting and was found to be free of cultural and educational biases $[20,22]$. A recent systematic review indicated that the Mini-Cog could be used as an alternative tool to the Mini-Mental State Examination (MMSE) with better sensitivity and specificity although further studies were suggested to provide better evidence on the diagnostic accuracy [23, 24]. It consists of two components, a recall task of three unrelated words and a clockdrawing test $(C D T)$. Scores range from 0 to 5 . Each recalled word scores 1 point. For CDT scores, 2 points are scored for a normal CDT. Since there are different ways to administer the CDT, the most commonly used method was used [25]. Pilgrims were asked to draw the circle, write the clock numbers, and draw the clock hands indicating the time of 10:11. A normal CDT was considered if all time numbers were correctly written and the hand positions pointed to the specified time (10: 11). Otherwise, 0 for poorly or partially performed CDT was recorded. A recent systematic review reported a high accuracy of the CDT in the diagnosis of dementia [26]. For Arab elderly, scores of the CDT was found to show significant correlations with scores of the MMSE supporting the validity of the CDT for Arab elderly [27].

The ADL instrument is a questionnaire that screens elderly respondents for physical functioning and assesses the degree of dependence in their daily activities [28]. There are mainly two types of ADL, the basic and the instrumental [29]. The instrumental ADL (IADL) impairment is often apparent in mild to moderate cognitive impairment, while the basic ADL impairment may not 
be evident unless the cognitive impairment is severe. Since we did not find a validated Arabic IADL instrument, the validated ADL instrument by Ramzi Nasser and Jacqueline Doumit [21] was used. The instrument assesses six functional domains, which are dressing, bathing, going to the toilet, transferring, continence, and feeding. Each domain has a score of 0 (complete dependence), 0.5 (partial independence), or 1 (complete independence). The total scores of all six domains were summed, divided by 6 , and then multiplied by 100 . A score of 67 or above indicates "no or mild dependence", 34 to 66 indicates "moderate dependence" and 0 to 33 indicates "severe dependence". A score of 100 was also categorized as "full independence".

\section{Statistical analysis}

SPSS, version 21.0 was used for all statistical analysis. Numeric data were presented as mean \pm SD and range according to the type of distribution of each variable. For categorical variables, percentages were used. Comparison between groups made among pilgrim by Student's $t$ test, the Mann-Whitney test or the KruskalWallis test according to data distribution and the number of compared groups. Chi-squared test was used for comparing categorical values. A Spearman's rankorder correlation was run to examine the correlation between the scores of the MINI-Cog and the ADL.

To determine predictors for positive MINI-Cog, univariate logistic regression was used. Afterwards, significant predictors found in univariate analysis were analysed in multivariate logistic regression to determine their interaction effect on the response variable (positive MINI-Cog). Statistical significance was set at $P<0.05$.

\section{Results}

\section{Demographics}

The mean age of all pilgrims was 66.26 years (SD 5.9). Male pilgrims were $54.1 \%(P .129)$. Most of the pilgrims were married $85.6 \%(P<.001)$. Pilgrims were from the following countries, in alphabetical order, Algeria 7.4\%, Bahrain 1.8\%, Egypt 9.1\%, Eritrea 4.1\%, Iraq 6.2\%, Jordan 6.5\%, Kuwait 1.5\%, Lebanon 6.8\%, Libya 7.1\%, Morocco $5.9 \%$, Oman $4.1 \%$, Palestine $7.4 \%$, Saudi $1.8 \%$, Sudan $5.9 \%$, Syria 7.6\%, Tunisia $7.9 \%$ and Yemen $9.1 \%$. Regarding educational attainment, $29.7 \%$ of pilgrims can read and write, another $29.7 \%$ had primary school level, $21.2 \%$ had intermediate or secondary school level and $19.4 \%$ had some undergraduate and postgraduate studies.

Almost half $(46.8 \%)$ of the pilgrims came with their spouses, $21.5 \%$ came alone, $21.5 \%$ came with their children, $11.2 \%$ with their siblings and $7.4 \%$ came with their friends. Most pilgrims came to Hajj as their second time Hajj (75\%) or their third time (13.5\%). Only $2.4 \%$ of pilgrims came to Hajj as their first time. Around third of pilgrims stated that they need someone to help them in performing their Hajj rituals $32.6 \%$. This help was sought more often by their children $13.2 \%$ than spouses $7.1 \%$, friends $7.1 \%$, Hajj organizing staff $6.5 \%$ or siblings $3.2 \%$. Only seven pilgrims reported the need for help from multiple sources (2.1\%). The type of help mentioned include help in walking, keeping track of Hajj rituals, circumambulation and throwing pebbles in Mina.

Regarding their medical history, pilgrims reported having hypertension $42.6 \%$, diabetes mellitus $32.1 \%$, hyperlipidemia $15.3 \%$, benign prostate hypertrophy (BPH) $2.6 \%$ and other conditions such as osteoarthritis, heart failure and allergies $2.6 \%$. Also, $1.8 \%$ of pilgrims stated visiting a clinic for memory problems, but neither stated being diagnosed with dementia nor taking any medication.

\section{MINI-Cog test}

Those pilgrims who scored 3 or fewer in the MINI-Cog were considered positive. Out of the 340 pilgrims, 29.2\% have positive scores in the MINI-Cog indicating probable cognitive impairment. Demographics and clinical characteristics of pilgrims with positive and negative MINI-Cog are presented in Table 1. Scores of the word recall and the CDT are presented in Table 2.

Pilgrims with positive MIN-Cog were older $(P<.05)$, have lower education levels $(P<.001)$, needed more help in performing Hajj $(P<.001)$, sought help more often by their children $(P<.05)$ and were seen more often in a cognitive clinic $(P<.05)$ than pilgrims with negative MINI-Cog.

No significant differences between pilgrims with positive MINI-Cog and negative MINI-Cog were found in regard to gender, marital status, the number of performed Hajj, medical conditions and categories of the ADL. However, based on Spearman's rank-order correlation, the scores of the MINI-Cog and the total scores of the ADL were found to be significantly correlated. The correlation was in the positive direction but weak $\left(r_{\mathrm{s}}=0.134, P=0.013\right)$.

\section{Binary logistic regression analysis}

We analysed predictors of positive MINI-Cog results using univariate and multivariate analyses. In univariate analysis, age, educational levels and need for help in performing Hajj were found significant (Table 3). Subsequently, in a multivariate analysis, we examined the significant predictors found in the univariate analysis. We found that the educational level and the need for help in performing Hajj significant predictors (Table 4). 
Table 1 Demographic and clinical characteristics of Hajj pilgrims with and without positive MINI-Cog test

\begin{tabular}{|c|c|c|c|}
\hline Total number $=340$ & Positive MINI-Cog $(N, \%)$ & Negative MINI-Cog $(N, \%)$ & $P$ \\
\hline & $99(29.2 \%)$ & $241(70.9 \%)$ & $<.001$ \\
\hline Age mean (SD) & $67.44(7.3)$ & $65.77(5.2)$ & 0.039 \\
\hline Gender & Male 49 (49.5\%) & Male 135 (56\%) & 0.273 \\
\hline Marital status & & & 0.314 \\
\hline Single & $4(4 \%)$ & $5(2.1 \%)$ & \\
\hline Married & $81(81.8 \%)$ & $210(87.1 \%)$ & \\
\hline Widow & $14(14.1 \%)$ & $26(10.8 \%)$ & \\
\hline Divorced & 0 & $3(1.2 \%)$ & \\
\hline Education level & & & $<.001$ \\
\hline Read and write & $55(55.6 \%)$ & $46(19.1 \%)$ & \\
\hline Primary school & $26(26.3 \%)$ & $75(31.1 \%)$ & \\
\hline Intermediate/secondary school & $11(11.1 \%)$ & $61(25.3 \%)$ & \\
\hline Undergraduate & $7(7.1 \%)$ & $54(22.4 \%)$ & \\
\hline Postgraduate & 0 & $5(2.1 \%)$ & \\
\hline \multicolumn{4}{|l|}{ Travelled with } \\
\hline Alone & $27(27.3 \%)$ & $46(19.1 \%)$ & 0.095 \\
\hline Spouse & $35(35.1 \%)$ & $124(51.5 \%)$ & 0.007 \\
\hline Siblings & $13(13.1 \%)$ & $25(10.1 \%)$ & 0.463 \\
\hline Children & $24(24.2 \%)$ & $49(20.3 \%)$ & 0.425 \\
\hline Friends & $8(8.1 \%)$ & $17(7.1 \%)$ & 0.742 \\
\hline Others & 1 nephew (1\%) & 0 & \\
\hline \multicolumn{4}{|l|}{ Helping in performing Hajj } \\
\hline No & $53(53.5 \%)$ & $173(73 \%)$ & \\
\hline Yes, by & $46(46.5 \%)$ & $65(27 \%)$ & $<.001$ \\
\hline Spouse & $7(7.1 \%)$ & $17(7.1 \%)$ & 0.996 \\
\hline Siblings & $5(5.1 \%)$ & $6(2.5 \%)$ & 0.225 \\
\hline Children & $19(19.2 \%)$ & $26(10.8 \%)$ & 0.038 \\
\hline Friends & $11(11.1 \%)$ & $13(5.4 \%)$ & 0.062 \\
\hline Hajj mission staff & $9(9.1 \%)$ & $13(5.4 \%)$ & 0.208 \\
\hline Others & 0 & 0 & \\
\hline Number of performed Hajj & & & 0.376 \\
\hline 0 & $2(2.0 \%)$ & $6(2.5 \%)$ & \\
\hline 1 & $78(78.8 \%)$ & $177(73.4 \%)$ & \\
\hline 2 & $12(12.1 \%)$ & $34(14.1 \%)$ & \\
\hline 3 & $5(5.1 \%)$ & $16(6.6 \%)$ & \\
\hline 4 or $>$ & $2(2 \%)$ & $8(3.3 \%)$ & \\
\hline \multicolumn{4}{|l|}{ Medical condition } \\
\hline DM & $30(30.3 \%)$ & $79(32.8 \%)$ & 0.657 \\
\hline HTN & $41(41.2 \%)$ & $104(43.2 \%)$ & 0.768 \\
\hline Hyperlipidemia & $12(12.1 \%)$ & $40(16.6 \%)$ & 0.298 \\
\hline $\mathrm{BPH}$ & $1(1 \%)$ & $8(3.3 \%)$ & 0.428 \\
\hline Other & $2(2 \%)$ & $7(2.9 \%)$ & \\
\hline \multicolumn{4}{|l|}{ Was seen in cognitive clinic } \\
\hline Yes & $4(4 \%)$ & $2(0.8 \%)$ & 0.041 \\
\hline
\end{tabular}


Table 1 Demographic and clinical characteristics of Hajj pilgrims with and without positive MINI-Cog test (Continued)

\begin{tabular}{lll}
\hline Total number $=340$ & Positive MINI-Cog $(\mathrm{N}, \%)$ & Negative MINI-Cog $(\mathrm{N}, \%)$ \\
\hline ADL scale & $1(1 \%)$ & 0 \\
Severe dependence & $1(1 \%)$ & $3(1.2 \%)$ \\
Moderate dependence & $30(30.3 \%)$ & $52(21.6 \%)$ \\
Mild dependence & $67(67.7 \%)$ & $186(77.2 \%)$ \\
Full independence & & \\
MINI-Cog test score & $8(2.4 \%)$ & - \\
0 & $33(9.7 \%)$ & - \\
1 & $58(17.1 \%)$ & - \\
2 & - & $79(23.2 \%)$ \\
3 & - & $57(16.8 \%)$ \\
4 & - & $105(30.9 \%)$ \\
5 & & \\
\hline
\end{tabular}

Values in italic are significant at the $5 \%$ level

$D M$ : diabetes mellitus, $H T N$ : hypertension, $B P H$ : benign prostate hypertrophy, ADL: activities of daily living

\section{Discussion}

We found an unexpectedly high level of probable cognitive impairment (29.2\%) in our sample. This exceeded the estimated prevalence of dementia worldwide (5-7\%) reported by a recent systematic review [7]. However, the systematic review included only studies utilizing diagnostic assessment, and the main pool of data had only two inclusive studies from the Middle East/African region. Nonetheless, another study reported a prevalence of $14.7 \%$ of probable cognitive impairment or dementia using the MINI-Cog in a community setting [30]. As mentioned earlier, prevalence rates of dementia and cognitive impairment in the $\mathrm{ME}$ are lacking, and there is an apparent need for research in this area.

One explanation of the high rate in our sample can be contributed to the educational level. In our sample, around $60 \%$ of pilgrims had primary school level or lower. Those who scored positive in the MINI-Cog reported either attaining primary school level (25\%) or can only read and write (55\%). Similarly, a validation

Table 2 Scores of word recall and clock-drawing test

\begin{tabular}{lll}
\hline MINI-Cog result & Word recall scores & Clock-drawing test scores \\
\hline Positive MINI-Cog & & \\
& $017(17.2 \%)$ & $090(90.2 \%)$ \\
& $133(33.3 \%)$ & $29(9.1 \%)$ \\
& $249(49.5 \%)$ & \\
& 30 & \\
Negative MINI-Cog & & $040(16.6 \%)$ \\
& 00 & $2201(83.4 \%)$ \\
& $139(16.2 \%)$ & \\
& $3145(23.7 \%)$ & \\
\hline
\end{tabular}

study done in Qatar found a high level of positive scores in the MINI-Cog (58.2\%) where $61.9 \%$ of their sample did not attend school [31]. Another finding in our study is that $90.2 \%$ of those who scored positive in the MINICog failed to perform the CDT accurately. This may reflect either the low performance of the CDT in the elderly with low educational levels [32] or the actual cognitive impairment as other studies found the CDT a reliable measure for the low educated elderly population [27].

Regarding risk factors for cognitive impairment, we found older age, lower educational levels and needing help in performing Hajj as significant predictors in the univariate analysis. However, in multivariate analysis, we found lower educational levels and needing help in performing Hajj significant. A recent systematic review [33] found older age and educational levels among the significant risk factors for dementia supporting our findings. For the need for help during Hajj, pilgrims stated needing help in walking, keeping track of Hajj rituals, circumambulation, and throwing pebbles in Mina. These activities include both the basic and instrumental ADL. Since the basic ADL are often not evident until the severe form of cognitive impairment develops [34], the basic ADL of the pilgrims was not found different between pilgrims with positive MIN-Cog and negative MINI-Cog. However, a weak positive correlation of the ADL scores and the MINI-Cog scores was found, which might indicate better ADL performance to be associated with better cognition.

The major strength of the study is the presenting of a varied multi-culture sample within Arabic-speaking pilgrims. It is the first study that explored the cognitive impairment in Arabic-speaking pilgrims. However, there are limitations to our study. First, we used only one 
Table 3 Significant odd ratios and 95\% Cl from univariate logistic regression analysis predicting positive MINI-Cog

\begin{tabular}{llll}
\hline Variable & Odd ratio & $95 \% \mathrm{Cl}$ & Sig \\
\hline Age & 1.047 & 1.008 to 1.088 & .019 \\
Educational level & 0.43 & 0.329 to 0.563 & $<.0001$ \\
Need help in performing Hajj & 0.426 & 0.262 to 0.692 & $<.001$ \\
\hline
\end{tabular}

screening tool to detect cognitive impairment, which may not be suitable for elderly with low educational levels [31, 35]. However, other studies reported better sensitivity and specificity of the MINI-Cog in elderly with low educational levels in comparison with other cognitive screening instruments [20, 36]. Second, we did not gather detailed medical history and other cognitive risk factors in order to evaluate the association between these factors and cognitive impairment. Third, the MINI-Cog test is a screening tool and not a diagnostic instrument which may have resulted in false-positive cases among all pilgrims who have been screened positive. The MINI-Cog test reflects the "probable cognitive impairment" but not those who have a diagnosis of dementia. Fourth, although impairment in the ADL correlates with cognitive impairment, this may not be apparent until severe cognitive impairment is evident. Instruments that assess IADL can provide better detection for the impact of cognitive impairment [29].

For future research, we suggest exploring multiple validated Arabic screening tools along with diagnostic assessments in order to determine the best screening tool for cognitive impairment among Arabic-speaking Hajj pilgrims. We also suggest investigating the use of the MINI-Cog as a screening tool collected by nonclinical professionals and its accuracy compared to a standard diagnostic tool or an assessment and its impact on proactive interventions. Suggested proactive interventions to be explored by future research include using mobile apps to detect pilgrim location, ensuring the presence of assistance, grouping those with cognitive impairment together under the care of specialized professionals, and support group for caregivers.

\section{Conclusion}

Cognitive impairment among elderly Arabic-speaking pilgrims was found to be common. Almost 30\% of the elderly pilgrims were found to have probable cognitive impairment. The scores of the MINI-Cog correlated

Table 4 Significant odd ratios and 95\% Cl from multivariate logistic regression analysis predicting positive MINI-Cog

\begin{tabular}{llll}
\hline Variable & Odd ratio & $95 \%$ Cl & Sig \\
\hline Educational level & 0.456 & 0.346 to 0.598 & $<.0001$ \\
Need help in performing Hajj & 0.581 & 0.342 to 0.984 & 0.044 \\
\hline
\end{tabular}

significantly with the scores of the ADL, indicating a significant association between the cognitive impairment and the degree of dependence in ADL. Future studies are needed to investigate the extent of cognitive impairment using different cognitive screening tools or diagnostic assessments along with the impact of cognitive impairment on the performance of Hajj pilgrims.

\section{Acknowledgements \\ Not applicable.}

\section{Authors' contributions}

Study conception and design: All authors. Acquisition of data: All authors. Analysis and interpretation of data: Ahmad Alzahrani. Drafting of manuscript: All authors. Critical revision and final approval: All authors. All authors read and approved the final manuscript.

Funding

No source of funding for the study.

Availability of data and materials

Data are available upon request. Please contact the corresponding author.

\section{Ethics approval and consent to participate}

A written consent was taken from all participants after explaining the details, benefits, and risks to them. The study was approved by the Ethics

Committee of Security Forces Hospital Program - Makkah (No. 0124-210817) on 24 August 2017.

\section{Consent for publication}

Not applicable.

\section{Competing interests}

The authors declare that they have no competing interests.

\section{Author details}

${ }^{1}$ Mental Health Administration, Neuroscience Center, King Abdullah Medical City, Makkah, Saudi Arabia. ${ }^{2}$ Neuroscience Department, King Faisal Specialist Hospital and Research Center, Jeddah, Saudi Arabia. ${ }^{3}$ College of Medicine, Umm Al Qura University, Makkah 24381, Saudi Arabia.

Received: 22 May 2019 Accepted: 26 August 2019

Published online: 12 September 2019

\section{References}

1. Hu C, Yu D, Sun X, Zhang M, Wang L, Qin H. The prevalence and progression of mild cognitive impairment among clinic and community populations: a systematic review and meta-analysis. Int Psychogeriatr. 2017; 29(10):1595-608.

2. Alzheimer's Disease International. Dementia statistics Available from: https:// www.alz.co.uk/research/statistics.

3. Bhalla D, Lotfalinezhad E, Amini F, Salmannejad M, Reza Borhani Nezhad V, Rezai Kooshalshah SF, et al. Incidence and risk profile of dementia in the regions of Middle East and North Africa. Neuroepidemiology. 2018;50(3-4): 144-52.

4. Amr M, El-Gilany A, Sallam K, Shams T. Characteristics of patients with dementia attended in a tertiary outpatient clinic in Eastern Region, Saudi Arabia. J Psychiatry. 2014;17(6):13.

5. Elshahidi MH, Elhadidi MA, Sharaqi AA, Mostafa A, Elzhery MA. Prevalence of dementia in Egypt: a systematic review. Neuropsychiatr Dis Treat. 2017;13: $715-20$.

6. Afgin AE, Massarwa M, Schechtman E, Israeli-Korn SD, Strugatsky R, Abuful A, et al. High prevalence of mild cognitive impairment and Alzheimer's disease in Arabic villages in northern Israel: impact of gender and education. J Alzheimers Dis. 2012;29(2):431-9.

7. Prince $M$, Bryce $R$, Albanese E, Wimo A, Ribeiro W, Ferri CP. The global prevalence of dementia: a systematic review and metaanalysis. Alzheimers Dement. 2013;9(1):63-75.e2. 
8. Yaghmour SM, Bartlett R, Brannelly T. Dementia in Eastern Mediterranean countries: a systematic review. Dementia (London). 2018:1471301217753776.

9. General authority for statistics. Hajj (Pilgrimage) Statistics Map - 14382017 Available from: https://hajmap.stats.gov.sa/indexmapeng1438.asp.

10. Al-Tawfiq JA, Memish ZA. The Hajj: updated health hazards and current recommendations for 2012. Eurosurveillance. 2012;17(41):20295.

11. Alzahrani AS, Alqahtani AM, Elmorsy SA, Alhazmi M, Mahdi HA, Albarakati B, et al. Prevalence of psychiatric disorders in Hajj pilgrims using MINI as a diagnostic tool. J Public Health. 2019:1-7.

12. Caidi N. Pilgrimage to Hajj: an information journey. Int J Inform Divers Inclusion. 2019;3(1).

13. Omar M, PS L, FS L. Cognitive function of elderly Haj pilgrims in Malaysia. Malays J Psychiatry. 2006;15(2):18 to 21.

14. Mograbi DC, Morris RG, Fichman HC, Faria CA, Sanchez MA, Ribeiro PCC, et al. The impact of dementia, depression and awareness on activities of daily living in a sample from a middle-income country. Int J Geriatr Psychiatry. 2018;33(6):807-13.

15. Sousa RM, Ferri CP, Acosta D, Albanese E, Guerra M, Huang Y, et al. Contribution of chronic diseases to disability in elderly people in countries with low and middle incomes: a 10/66 Dementia Research Group population-based survey. Lancet. 2009;374(9704):1821-30.

16. van de Vorst IE, Vaartjes I, Geerlings MI, Bots ML, Koek HL. Prognosis of patients with dementia: results from a prospective nationwide registry linkage study in the Netherlands. BMJ Open. 2015;5(10):e008897.

17. Sörensen S, Conwell Y. Issues in dementia caregiving: effects on mental and physical health, intervention strategies, and research needs. Am J Geriatr Psychiatry. 2011;19(6):491-6.

18. Nelis SM, Wu Y-T, Matthews FE, Martyr A, Quinn C, Rippon I, et al. The impact of co-morbidity on the quality of life of people with dementia: findings from the IDEAL study. Age Ageing. 2018;48(3):361-7.

19. Fernando E, Fraser M, Hendriksen J, Kim CH, Muir-Hunter SW. Risk Factors Associated with Falls in older adults with dementia: a systematic review. Physiother Can. 2017;69(2):161-70.

20. Borson S, Scanlan J, Brush M, Vitaliano P, Dokmak A. The mini-cog: a cognitive 'vital signs' measure for dementia screening in multi-lingual elderly. Int J Geriatr Psychiatry. 2000;15(11):1021-7.

21. Nasser R, Doumit J. Validity and reliability of the Arabic version of activities of daily living (ADL). BMC Geriatrics. 2009;9:11.

22. Borson S, Scanlan JM, Lessig M, Watanabe J, Tu SP. Simplifying detection of cognitive impairment: Comparison of the Mini-Cog and Mini-Mental State Examination in a multiethnic sample. J Am Geriatrics Soc. 2005;53(5):871-4.

23. Fage BA, Chan CC, Gill SS, Noel-Storr AH, Herrmann N, Smailagic N, et al. Mini-Cog for the diagnosis of Alzheimer's disease dementia and other dementias within a community setting. Cochrane Database Syst Rev. 2015;2: CD010860.

24. Seitz DP, Chan CC, Newton HT, Gill SS, Herrmann N, Smailagic N, et al. MiniCog for the diagnosis of Alzheimer's disease dementia and other dementias within a primary care setting. Cochrane Database Syst Rev. 2018;2: Cd011415.

25. Shulman Kl. Clock-drawing: is it the ideal cognitive screening test? Int J Geriatr Psychiatry. 2000;15(6):548-61.

26. Park J, Jeong E, Seomun G. The clock drawing test: a systematic review and meta-analysis of diagnostic accuracy. J Adv Nurs. 2018;74(12):2742-54.

27. Merims D, Ben Natan M, Milawi D, Boguslavsky T. The clock-drawing test: normative data in adult and elderly Israeli Arabs. Psychogeriatrics. 2018; 18(3):175-81.

28. Katz S, Ford AB, Moskowitz RW, Jackson BA, Jaffe MW. Studies of Illness in the Aged. The index of ADL: a standardized measure of biological and psychosocial function. JAMA. 1963;185:914-9.

29. Mlinac ME, Feng MC. Assessment of activities of daily living, self-care, and independence. Arch Clin Neuropsychol. 2016;31(6):506-16.

30. Bayley PJ, Kong JY, Mendiondo M, Lazzeroni LC, Borson S, Buschke H, et al. Findings from the National Memory Screening Day program. J Am Geriatr Soc. 2015;63(2):309-14.

31. Albanna M, Yehya A, Khairi A, Dafeeah E, Elhadi A, Rezgui L, et al. Validation and cultural adaptation of the Arabic versions of the MiniMental Status Examination - 2 and Mini-Cog test. Neuropsychiatr Dis Treat. 2017;13:793-801.

32. Lourenco RA, Ribeiro-Filho ST, Moreira Ide F, Paradela EM, Miranda AS. The clock drawing test: performance among elderly with low educational level. Rev Bras Psiquiatr. 2008;30(4):309-15.
33. Livingston G, Sommerlad A, Orgeta V, Costafreda SG, Huntley J, Ames D, et al. Dementia prevention, intervention, and care. Lancet. 2017;390(10113): 2673-734.

34. West S, Fonseca F, Rice J, McCue R, Golden C, editors. Does memory predict decline in activities of daily living in older adults with Alzheimer's disease? Archives of clinical neuropsychology. OXFORD: Oxford Univ Press; 2010.

35. Ribeiro Filho ST, Lourenço RA. The performance of the Mini-Cog in a sample of low educational level elderly. Dement Neuropsychol. 2009;3:81-7.

36. Milian M, Leiherr AM, Straten G, Muller S, Leyhe T, Eschweiler GW. The MiniCog versus the Mini-Mental State Examination and the Clock Drawing Test in daily clinical practice: screening value in a German Memory Clinic. Int Psychogeriatr. 2012;24(5):766-74.

\section{Publisher's Note}

Springer Nature remains neutral with regard to jurisdictional claims in published maps and institutional affiliations.

\section{Submit your manuscript to a SpringerOpen ${ }^{\circ}$ journal and benefit from:}

- Convenient online submission

- Rigorous peer review

- Open access: articles freely available online

High visibility within the field

- Retaining the copyright to your article

Submit your next manuscript at $\boldsymbol{\nabla}$ springeropen.com 